\title{
Study on the extraction of polyphenol from Artocarpus altilis with ultrasonic wave technology optimized by central composite design-response surface method
}

\author{
Dam Sao Mai \\ Institute of Biotechnology and Food Technology, Industrial University of Ho Chi Minh City, Ho Chi Minh City, Vietnam
}

Email address:

damsaomai@gmail.com

To cite this article:

Dam Sao Mai. Study on the Extraction of Polyphenol from Artocarpus Altilis with Ultrasonic Wave Technology Optimized by Central Composite Design-Response Surface Method. Journal of Food and Nutrition Sciences. Special Issue: Food Processing and Food Quality. Vol. 3, No. 1-2, 2015, pp. 115-118. doi: 10.11648/j.jfns.s.2015030102.32

\begin{abstract}
Response surface methodology (RSM) was used to optimize ultrasonic-assisted extraction for total polyphenols from Artocarpus altilis based on single-factor experiment. The main factors, ultrasonic time, the liquid-solid ratio, the extraction temperature, the type of addition acid of single factor experiment was surveyed; the principle of design for 2 factors (extraction time and liquid-solid ratio) 2 levels response surface methodology was applied and the response surface optimization extraction conditions were studied. The ultrasonic wave frequency of $37 \mathrm{kHz}$ at $550 \mathrm{~W}$ power, the ethanol concentration of $70^{\circ}$, the extracting temperature of $75^{\circ} \mathrm{C}$, the extracting time of 35 minutes, and the ratio of solvent volume of 13.9:1 (Extracted 4 times) at $\mathrm{pH} 3.5$ were selected as the optimum conditions, the extraction yield of polyphenols was $391.5862 \mathrm{mg} / \mathrm{g}(\mathrm{P}<0.05)$. Ultrasonic extraction is a good method for saving time, energy and material, and can be applied to the polyphenols extraction. This result revealed that potent of utilization low-value material to produce the polyphenol product at industrial scale.
\end{abstract}

Keywords: Artocarpus Altilis, Polyphenols, Ultrasonics, Optimazation, Antioxidant

\section{Introduction}

The consumption of polyphenols can be $1 \mathrm{~g} /$ day that is higher than vitamin $\mathrm{C}$ demanding; are about $10-100$ times more than vitamin $\mathrm{E}$ and carotene (Ragon, 1997). Polyphenols are considered the products, which have economic and biologically value. In particular, the leaves of breadfruit (Artocarpus altilis) contain high levels of polyphenols and have not been used much in the market. Artocarpus altilis is in the Moraceae crops. Leaves have antibacterial, inflammatory, diuretic characteristics. According to the American Cancer Society, polyphenols help prevent the risk of cancer, high blood pressure, heart disease ... (Ragon, 1997).

In this study, the polyphenols were extracted from leaf of breadfruit with suitable solvent in combination with ultrasound based on the principle of high-frequency ultrasound.

\section{Materials and Methods}

Materials: Leaves of breadfruit were used in this study collecting from: Lot C40 -43 / I, C551 - 55/II, Street 7th, Vinh Loc Industrial Zone, Binh Chanh, HCMC, Vietnam. The yellow leaves were collected and selected. After acquisition leaves were been taken reluctantly to dry, shrink and then dried. Dried leaves were preserved in a dry and cool place.

\section{Methodology}

Extraction method: Leaves of breadfruit were extracted in $100 \mathrm{~mL}$ solvent, and then filtered in vacuum filtration, centrifuged in 20 minutes with the speed of $6000 \mathrm{r} / \mathrm{min}$. The obtained liquid was taken to analysis.

Survey the optimized polyphenol extraction: The selected breadfruit leaves were treated in different extraction time (5, $10,15,20,25$ minutes), at different temperature $(40,50,60$, $\left.70,80^{\circ} \mathrm{C}\right)$, with different ratio of raw material and chosen solvent $(1: 9,1: 11,1: 13,1: 15,1: 17(\mathrm{w} / \mathrm{v})$, with different adjusted acid (ascorbic acid, citric acid, acetic acid, $\mathrm{HCl}$ ), in different time of extraction $\left(1^{\text {st }}, 2^{\text {nd }}, 3^{\text {rd }}, 4^{\text {th }}\right)$ 
Analysis: The moisture and ash content of materials was determined (Nguyen Thi Hien et al, 2010). Total polyphenols were analyzed by Folin - Denis method (Swain \& Hillis, 1959).

Statistical analysis: All measurements were done in triplicate. Using Modde 5 software to perform optimization. Analyses of Variance (ANOVA) were conducted by using SPSS Version 13.0 for Windows (SPSS). Turkey tests were performed to test the significant differences between the mean values for treatments $(\mathrm{p}<0.05)$

\section{Results and Discussion}

Effect of the extraction time of using ultrasound on the polyphenols extraction

The frequency of ultrasonic $(37 \mathrm{kHz}, 550 \mathrm{~W}$ power), using ethanol of $70^{\circ}$, the rate of raw material/solvent at $1 / 15$, temperature of $70^{\circ} \mathrm{C}$ and $\mathrm{pH} 3.5$ were fixed. The extraction time of using ultrasound were changed from 5 to 45 minutes. The results are presented in Fig. 1. So the best extracted time was chosen at 35 minutes.

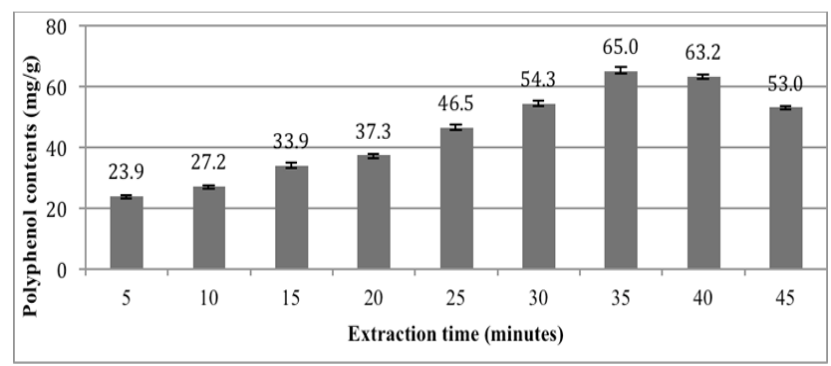

Fig. 1. Effect of the extraction time of using ultrasound on the concentration of extraction polyphenols (with interval 5 minutes)

When the treatment time was increased, the extraction efficiency also was increased. The highest level of polyphenol extraction was reached after 35 minutes and the amount of polyphenols was decreased in the next period because of the oxidization. When using ultrasound for extraction, after 35 minutes of treatment $65.0117 \mathrm{mg} / \mathrm{g}$ polyphenols were extracted. This result was much higher than the control sample (receiving $38.988 \mathrm{mg} / \mathrm{g}$ ), which was using the similar method but without using ultrasonic.

Effect of the extraction temperature of using ultrasound on the polyphenols extraction



Fig. 2. Effect of the extraction temperature of using ultrasound on the concentration of extraction polyphenols (with interval $10^{\circ} \mathrm{C}$ )
The frequency of ultrasonic $(37 \mathrm{kHz}, 550 \mathrm{~W}$ power $)$, using ethanol of $70^{\circ}$, the rate of raw material/solvent at $1 / 15, \mathrm{pH}$ 3.5 and selected extraction time of 35 minutes were fixed. The extraction temperature of using ultrasound was changed from 40 to $80^{\circ} \mathrm{C}$ with interval of $10^{\circ} \mathrm{C}$. The results are presented in Fig 2.

When the treatment temperature was increased, the extraction efficiency also was increased. The highest level of extraction was reached at $70-80^{\circ} \mathrm{C}$. The received values at 70 and $80^{\circ} \mathrm{C}$ were increased but not significantly difference. The experiment with temperature was continued with shorter interval $\left(5^{\circ} \mathrm{C}\right)$ from 60 to $80^{\circ} \mathrm{C}$ to find out the better temperature for the polyphenol extraction. The results are presented in Fig. 3. The best-extracted temperature was chosen at $75^{\circ} \mathrm{C}$. If the temperature was higher, the extracted polyphenol began reduced by oxidization and structure breaking.

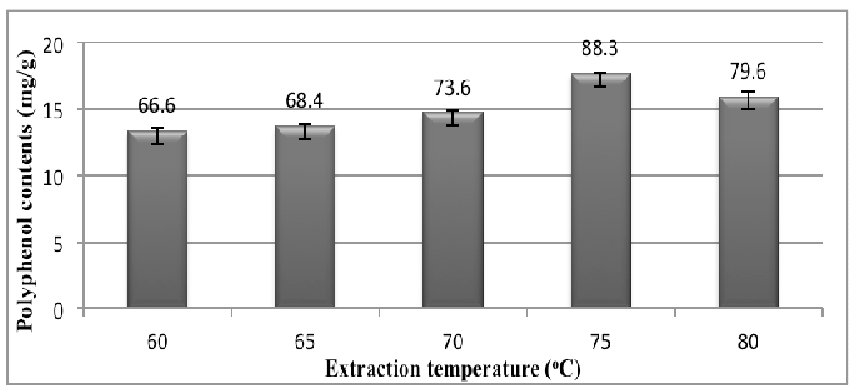

Fig. 3. Effect of the extraction temperature of using ultrasound on the concentration of extraction polyphenols (with interval $5^{\circ} \mathrm{C}$ )

Effect of the ratio between material and solvent on the polyphenols extraction

The frequency of ultrasonic $(37 \mathrm{kHz}, 550 \mathrm{~W}$ power $)$, using

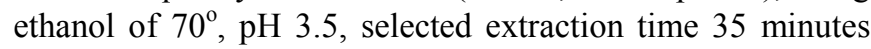
and temperature of $75^{\circ} \mathrm{C}$ were fixed. The ratio between material and solvent was changed, such as: 1:09, 1:11, 1:13, $1: 15,1: 17$. The results are presented in Fig. 4.



Fig. 4. Effect of the ratio between material and solvent on the concentration of extraction polyphenols

This survey investigated the ratio of material and solvent, which was used in the extraction. Fig. 4 showed that, when using unsuitable ratio of solvent, the received amount of polyphenols was not high enough. With ratio of material and solvent about: 1:13, 1:15, 1:17, the collected polyphenols were stable and nearly equivalent. Among these ratios, material and solvent was 1:13 was chosen. This result was used for the following surveys 
Effect of the suitable acid using on the polyphenols extraction

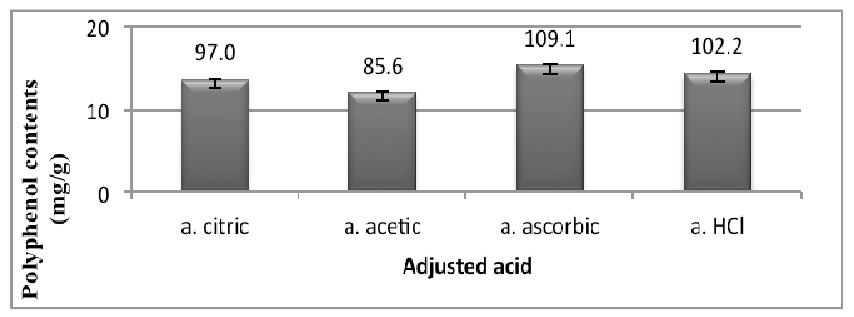

Fig 5. Effect of different adjusted acid on the concentration of extraction polyphenols

The frequency of ultrasonic $(37 \mathrm{kHz}, 550 \mathrm{~W}$ power), using ethanol of $70^{\circ}, \mathrm{pH} 3.5$, selected extraction time 35 minutes, temperature of $75^{\circ} \mathrm{C}$ and ratio between material and solvent of 1:13 were fixed. The studied acids were adjusted, such as: acid ascorbic, acid citric, acid acetic and $\mathrm{HCl}$. The results are presented in Fig. 5.

The highest amount of polyphenols was extracted when ascorbic acid was using and the lowest when acetic acid was using. The ascorbic acid is less stable, and easy to destroyed under the effect of light and heating process. Meanwhile, the acid citric is considered to use as food additives, preservatives, which is safe to use as natural ingredients. This acid also gave good result and not much different comparing with using ascorbic acid.

Using $\mathrm{HCl}$ also received the little higher amount of polyphenols but not much and not safety as using citric acid. So the citric acid was chosen to use to the other experiments.

Survey the optimal $\mathrm{pH}$ of the solvent for polyphenols extraction

The frequency of ultrasonic $(37 \mathrm{kHz}, 550 \mathrm{~W}$ power), using ethanol of $70^{\circ}$, selected extraction time of 35 minutes, temperature of $75^{\circ} \mathrm{C}$, ratio between material and solvent of 1:13, using citric acid for adding were fixed. The $\mathrm{pH}$ was changed, such as: $3.0,3.5,4.0,4.5,5.0$. The results are presented in Fig. 6.

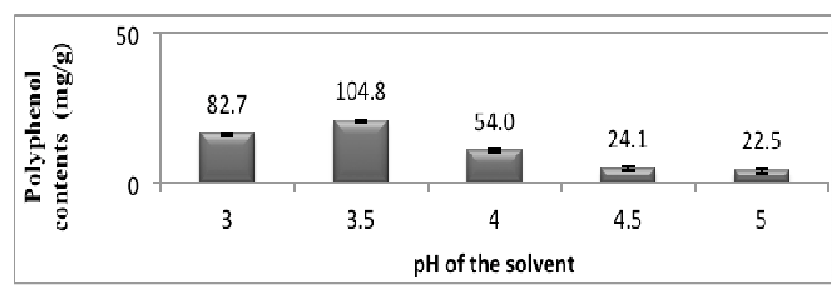

Fig. 6. Impact of $\mathrm{pH}$ on the concentration of extraction polyphenols

Survey the $\mathrm{pH}$ of the solvent which was used for polyphenol extraction from the breadfruit leaves with suitable solvent and optimal ratio. Fic. 6 showed that when the $\mathrm{pH}$ was high, the extracted polyphenol may be destroyed, so the received amounts were very low. The highest amount of polyphenols $(104.8 \%)$ obtained at $\mathrm{pH}$ of 3.5 . The results showed that with a $\mathrm{pH}$ of $<3.5$ and $>3.5$ the polyphenols extraction capabilities were descending. That result is similar with other researches.

Survey the times of ultrasonic for polyphenols extraction
After 4 times extraction, $391.5862 \mathrm{mg} / \mathrm{g}$ of polyphenols were extracted from 5 gram of material. With the control sample only $282.161 \mathrm{mg} / \mathrm{g}$ were extracted.

Survey the optimize of extraction time and extraction temperature

The experiment was conducted according to a central composite design, with the following variables: extraction time (30-40 min, center value was 35 minutes), material and solvent ratio $(1: 11-1: 15$, center value was $1: 13)$.

The optimal result was analyzed by Modde 5 (Fig.7) with $\mathrm{Q}^{2}=0.966>0.7$ and $\mathrm{R}^{2}=0.985>0.8$. The results were absolutely suitable with the optimal model. The regression equation of polyphenols extracted efficiency depending on the extraction time and material and solvent ratio was as following:

$$
\mathrm{Y}=120.01-2.328 \mathrm{X}_{1}+12.9 \mathrm{X}_{2}-7.185 \mathrm{X}_{1}^{2}-13.47 \mathrm{X}_{2}^{2}
$$

( $\mathrm{X}_{1}$ is the extraction time, $\mathrm{X}_{2}$ is the material and solvent ratio)
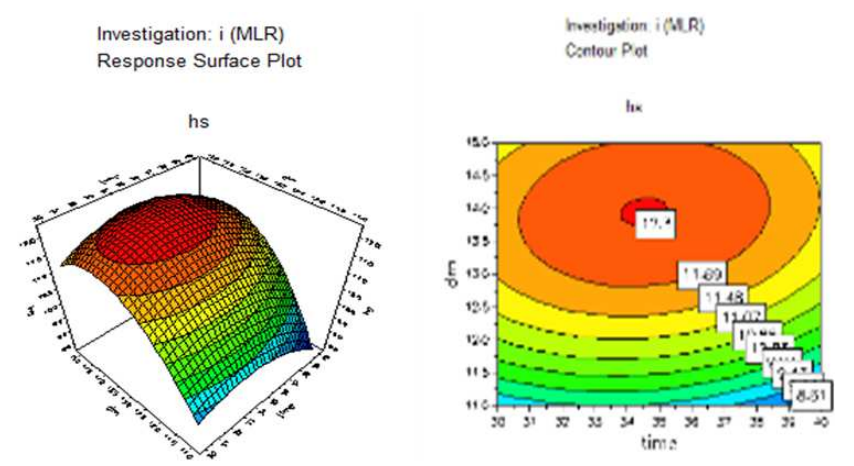

Fig. 7. Contour pilot and response surface pilot of survey the optimization of extraction time and material and solvent ratio.

Optimal results obtained after empirically verifiable were: the extraction time was $35 \mathrm{~min}$, material and solvent ratio was 1:13.9, and F value was 89.4886 . Results of polyphenols was $122.67 \mathrm{mg} / \mathrm{g}$.

To extract out all pigment, the enough time was necessary. However, the sample exposure to the oxygen in the air when extending the extraction time will change the structure of polyphenols molecule, and reduce the amount of the obtained color. Therefore, the extraction time must not be too long

With high rate of using solvent, more polyphenols would be extracted. The amount of polyphenols was extracted not much different between higher ratios than 1:13.9. Therefore, if solvent ratio is too low, it will decrease the extraction effect and extend the extraction time; while high ratio of solvent will be not commercial and taking time to concentrate the sample.

\section{Conclusion}

Many researchers found that the temperature, time, ratio of material and solvent are the factors affecting on the polyphenols extraction process, but have not analyzed with ultrasonic. The extraction method was using ultrasonic waves for total polyphenol content extraction with following 
parameters, such as: a frequency of $37 \mathrm{kHz}, 550 \mathrm{~W}$ power, with ethanol of $70^{\circ}$, at $75^{\circ} \mathrm{C}$, in 35 minutes, in the $1: 13.9$ of the ratio between material and solvent, at $\mathrm{pH} 3.5$ when using citric acid. In this extraction condition, the total polyphenols was received at $391.5862 \mathrm{mg} / \mathrm{g}$

\section{Acknowledgements}

Thank you for Mr. Truong Hoang Duy to help in my work.

\section{References}

[1] Nguyen Thi Hien et al. 2010. Food analysis. Labour publishing house, Vietnam.
[2] Nguyen Xuan Trinh, Nguyen Xuan Phuoc. 2013. Research on the polyphenol extraction from breadfruit leaves and using in producing the rich polyphenol beverage.

[3] Malkeet Singh Padda. 2006. Phenolic composition and antioxidant activity of sweetpotatoes, Punjab Agricultural University.

[4] Ragon D. 1997. "Breadfruit. Artocarpus altilis (Pakinson) Fosberg”, International plant Genetic Resources Institute. 